\title{
Índios Urbanos: Um estudo sobre as condições de vida dos Sateré-Mawé residentes na Casa de Trânsito Indígena de Parintins (AM)
}

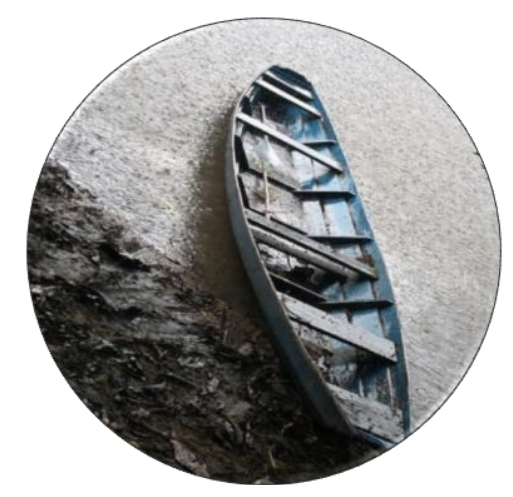

Maria de Lourdes Ferreira da Silva ${ }^{1}$

Milena Fernandes Barroso ${ }^{2}$

\section{Resumo}

O presente artigo visa discorrer sobre as condições de vida dos indígenas da Etnia Sateré-Mawé residentes na Casa de Trânsito Indígena de Parintins, município do Estado do Amazonas. A vivência em áreas urbanas configura novas formas de condições de vida, diferentes das vivenciadas em terras indígenas. Esse novo cenário vivido faz surgir à necessidade de se criar mecanismos próprios de interação com a sociedade envolvente, mas sem deixar de lado sua essência cultural.

Palavras-chave: Etnia Sateré-Mawé; Condições de Vida; Índios Urbanos.

\begin{abstract}
This article aims to discuss the living conditions of the Sateré-Mawé Indians living in the Indigenous Transit House of Parintins, a municipality in the State of Amazonas. Living in urban areas shapes new forms of living conditions, different from those experienced in indigenous lands. This new scenario presents the need to create its own mechanisms of interaction with the surrounding society, but without leaving aside its cultural essence.
\end{abstract}

Keywords: Sateré-Mawé Ethnicity; Life conditions; Urban Indians.

\footnotetext{
1 Assistente Social. Docente substituta do Curso de Serviço Social do Instituto de Ciências Sociais, Educação e Zootecnia da Universidade Federal do Amazonas - UFAM. Cursando Especialização em Saúde Pública e da Família. malusilferreira@gmail.com.

2 Docente do Curso de Serviço Social do Instituto de Ciências Sociais, Educação e Zootecnia da Universidade Federal do Amazonas - UFAM. Mestre em Serviço Social e Sustentabilidade na Amazônia. mi.barroso@yahoo.com.
} 


\section{Introdução}

O presente trabalho visa analisar as condições de vida dos indígenas da etnia Sateré-Mawé que residem na área urbana do município de Parintins/AM, especificamente na Casa de Trânsito Indígena. Atualmente existem cerca de 10.338 indígenas sateré-mawé habitando o leste do estado do Amazonas na divisa com o estado do Pará, compreendendo as regiões do Andirá-Marau, KoatáLaranjal e Uaicurapá (FUNASA/SIASI, 2010)³. Esses indígenas nos últimos anos têm se deslocado de suas aldeias de origem para buscar melhores condições de vida na cidade, porém, acabam por encontrar péssimas condições de vivência em meios urbanos.

A etnia Sateré-Mawé é organizada política, social, econômica e culturalmente conforme as tradições presentes na sua formação étnica. E, embora essa tenha passado por mudanças ao longo da história ainda apresenta referenciais arraigados a sua tradição, os quais direcionam o seu modo de vida. Dentre estes referenciais está a figura do tuxaua, o artesanato, o guaraná para fins de comércio e consumo próprio através do çapó e o Ritual da Tucandeira - rito de passagem do menino indígena para a fase adulta ${ }^{5}$.

\footnotetext{
3 Os sateré-mawé integram o tronco linguístico Tupi, sendo considerados como um dos clãs que constituem a estrutura social Tupinambá. Assim, como os demais clãs desse grupo, os sateré-mawé não operam como grupo corporado, mas encontram-se dispersos nas diversas comunidades como clãs multilocalizados. A existência desse grupo em terras amazônicas se deu através das migrações dos Tupinambás (ALVAREZ, 2009).

4 Atualmente, esses índios se definem eles mesmos como Sateré-Mawé. Sateré (nome do clã mais nobre, considerado no passado como o clã dos tuxauas: chefes da tribo), é um animal que parece com uma centopéia peluda. Mawé é o nome mais completo da tribo e também de um papagaio falante dessa região (BERNAL, 2009).

5 Os sateré-mawé obedecem a uma lógica cultural. Entre as características étnicas está o Tuxaua, este representa a autoridade da tribo, o chefe, o cacique. Toda tribo tem um tuxaua, o qual é considerado como responsável desta, pessoa investida de autoridade para mediar os conflitos internos, resolver e representar a tribo diante da sociedade ocidental. O artesanato é outro traço étnico sateré-mawé, dentre estes se destacam os teçumes, sendo sua maior expressão. "Eles designam por teçume o artesanato confeccionado pelos homens com talos e folhas [...], com os quais fazem peneiras, cestos, tipitis, abanos, bolsas, chapéus, paredes, coberturas de casas, etc." (LORENZ, 1992, p. 30). As mulheres também confeccionam artesanato usando sementes com destaque para colares, brincos e pulseiras, como se observou durante o período da pesquisa de campo. O Guaraná é um dos marcadores sateré-mawé que se relaciona com a economia e com a espiritualidade dos mesmos. Além de ser um produto
} 
$\mathrm{Na}$ cidade os indígenas se deparam com uma realidade diferente do contexto vivenciado nas comunidades indígenas. Essas diferenças têm raízes culturais, mas também sociais e econômicas, uma vez que quando os indígenas passam a morar na área urbana vivenciam geralmente situações precárias de trabalho, renda, moradia, saúde e educação. Essas situações são decorrentes quase sempre da dificuldade ou negação de acesso aos direitos assegurados em lei e através das políticas públicas.

Entre os principais motivos que levam os indígenas sateré-mawé a migrarem para a cidade está a procura por melhores condições de acesso, seja no que se refere à educação, saúde, moradia, dentre outros. Ocorre que a vivência em áreas urbanas, de acordo com Teixeira (2008), nem sempre proporciona melhores condições de acesso dos indígenas aos serviços ou políticas públicas existentes, na maioria das vezes a insuficiência destes traz opressões etnocêntricas, precarização do trabalho, entre outras refrações da questão social presentes no cotidiano urbano, os quais comprometem as condições de vida da população ${ }^{6}$.

Os povos indígenas, ao longo da história, sofreram um processo de dizimação causada pelo etnocentrismo dos não índios que acharam ser sua cultura a melhor, a mais correta. A literatura estudada nos mostra que, na sociedade contemporânea, as relações sociais, fruto do sistema capitalista, condicionam e determinam os indígenas a saírem de suas terras e constituírem moradia fixa nas áreas urbanas.

Frente a este panorama é importante assinalar que mesmo diante dessa nova conjuntura os indígenas que passaram a residir na Casa de Trânsito não deixaram de ser indígenas, mas a partir da convivência nesta agregaram a sua cultura novas formas, incluindo ideias, valores, sentimentos, enfim, novos sentidos.

comercializado serve para o consumo dos mesmos, pois do guaraná se faz o çapó, uma bebida utilizada no cotidiano, mas também para celebrações rituais.

${ }^{6}$ As refrações da questão social são as expressões das desigualdades da sociedade capitalista. Nesse sentido, as refrações formam este conjunto que por sua vez está definido como questão social. 
Para a elaboração deste trabalho foi utilizada a abordagem qualitativa com suporte dos dados quantitativos. A pesquisa foi desenvolvida em duas etapas interrelacionadas. A primeira, referente à pesquisa bibliográfica, e a segunda etapa, à pesquisa de campo. Os sujeitos da pesquisa foram 07 famílias saterémawé que mantinham residência na Casa de Trânsito Indígena no momento da pesquisa $^{7}$. Os instrumentos para a coleta de dados quantitativos foram questionários semiestruturados e entrevistas com um roteiro pré-estabelecido.

\section{A migração dos indígenas Sateré-Mawé para a Casa de Trânsito Indígena de Parintins}

A Casa de Trânsito Indígena, popularmente conhecida como Casa do Índio, pertence oficialmente à Diocese do município de Parintins, mas foi cedida aos indígenas para que estes pudessem se hospedar temporariamente, ocorre que, há mais de dez anos, famílias têm morado na Casa de forma permanente. Apesar de o espaço ter sido cedido aos indígenas sateré-mawé, a Diocese de Parintins, estabelece as regras de uso e convivência no interior da Casa. Entende-se que tal situação revela a continuidade de um processo de dependência estabelecida durante a colonização entre os indígenas e os missionários.

Dentre os motivos que levou as famílias sateré-mawé a migrarem para a Casa de Trânsito está a saúde com 28,54 \%, seguida de educação com 14,27 \%; a opção “outros motivos" apresentou 14,29\%. As outras opções elencadas no questionário como trabalho, casamento e perda da posse da terra não foram motivos que os fizeram vir para Parintins.

Partindo dos dados obtidos, entende-se que o fato de a saúde ser um dos principais motivos da migração indígena Sateré-Mawé se dá em razão da ausência nas comunidades de suporte médico e material para aqueles que possuem doenças que necessitam de atenção médica contínua e permanente. Este fato pôde ser verificado durante a pesquisa, como nos revela um dos nossos

\footnotetext{
${ }^{7}$ Esta pesquisa foi realizada no ano de 2011 e a discussão aqui sintetizada é parte integrante do Trabalho de Conclusão do Curso de Serviço Social do Instituto de Ciências Sociais, Educação e Zootecnia da Universidade Federal do Amazonas/UFAM.
} 
interlocutores: "Primeiramente nós viemos por motivo da minha filha ter uma doença que impediu ela de andar direito e ter que tomar remédio controlado. Ai, a mulher com dois filhos men ficaram aqui, depois ficaram pra estudar [...]” (JOSÉ, ENTREVISTA, 2011) .

Quanto à educação dos filhos, elencada como um dos motivos, compreende-se que o contato cada vez maior com a sociedade envolvente faz surgir nos indígenas o sentimento da importância da formação escolar. Bernal (2009, p. 161) assinala que:

A necessidade de estudar é a primeira razão expressa quando se trata
de falar da migração de um núcleo familiar. No imaginário de todas
as tribos amazônicas que tiveram contatos mais ou menos
prolongados e intensos com a sociedade nacional, a educação das
crianças é uma prioridade que determina fortemente o fluxo
migratório de grupos familiares inteiros. Na origem da criação dessa
ideologia, encontra-se o trabalho "civilizador" realizado pela igreja
Católica, mas também pelas forças armadas, pelos funcionários da
Funai, e, mais recentemente, por outros organismos, tais como as
Secretarias Municipais e Estaduais de Educação ou certas
organizações não-governamentais.

É dentro dessa realidade e sob essa ideologia que as famílias que passaram a residir na Casa de Trânsito vieram para Parintins. Para estes, a educação dos filhos é importante, uma vez que os estudos permitirão que os mesmos voltem para suas aldeias de origem para ali poderem contribuir com a sua família e a comunidade como um todo. Nesse sentido é importante destacar que nas comunidades “[...] o nível escolar oferecido não vai além da terceira série do ensino fundamental, os pais devem decidir se os filhos ficarão sem instrução suplementar ou se mandam eles para as cidades próximas para continuar seus estudos” (BERNAL, 2009, p. 161).

Durante a pesquisa, nos foi apresentado um motivo para a migração, não previsto anteriormente como elemento para análise a partir de umas famílias pesquisadas. Este motivo se refere à representação indígena, o qual se enquadrou na categoria "outros".

\footnotetext{
${ }^{8}$ Os nomes utilizados são fictícios a fim de preservar a identidade dos sujeitos da pesquisa.
} 
Em conversa com o responsável desta família este alegou que veio para a cidade por uma escolha e indicação das lideranças indígenas Sateré-Mawé e pelo tuxaua geral da Tribo. O senhor João refere-se a sua ida para Parintins, a partir da seguinte narrativa: "Vim para a cidade por escolba do tuxana geral que me nomeou para ser o coordenador responsável pela casa, para que eu pudesse tomar conta dela" (ENTREVISTA, 2011).

O fato de este indígena migrar para Parintins encarregado de uma obrigação/função política demonstra a autoridade que o tuxaua geral tem sobre seus parentes e se reflete no que expõe a pesquisa que Bernal (2009) realizou acerca dos índios urbanos em Manaus, o qual destaca que um dos motivos encontrados para os índios virem para a cidade se refere ao fato de terem sido "eleitos para representar suas associações ou organizações indígenas; é o caso do índio do sexo masculino. Para ele viver na cidade foi uma exigência da luta pela terra, pela organização, pelos direitos” (BERNAL, 2009, p. 161).

Os indígenas, visando consolidar direitos, deixam suas terras para fixar residência na cidade, a fim de lutar por políticas públicas para sua comunidade e para os próprios indígenas que residem nos centros urbanos.

Sendo assim, estes ao migrarem para Parintins, não tendo parentes ou moradia própria para morar, passam a residir na Casa de Trânsito Indígena. Ocorre que a vida na cidade apresenta condicionantes que implicam na permanência destes indígenas, dentre estes estão o desejo de continuidade dos estudos dos filhos e melhores serviços de saúde. Desse modo, os indígenas sateré-mawé acabam permanecendo por muito mais tempo. Essa permanência vai ter relação direta nas condições de vida desses indígenas, uma vez que a consolidação ou a negação de direitos através do acesso às políticas públicas influenciam diretamente nas condições de vida de uma população. 


\section{Caracterização geral das condições de vida dos Sateré-Mawé residentes na Casa de Trânsito Indígena de Parintins}

Para se falar em condições de vida é necessário levar em consideração alguns aspectos demográficos e socioeconômicos determinantes das condições de vida da população, os quais servem como indicadores sociais para mensurá-las? .

Os indicadores sociais utilizados neste trabalho, a fim de se verificar as condições de vida dessa população, se referem à educação (grau de instrução e oferta de educação escolar indígena), situação de trabalho e renda, composição da família/arranjos familiares, acesso aos serviços de saúde (ocorrência de doenças e cobertura dos serviços segundo a óptica dos indígenas) e habitação (condições de moradia). O primeiro indicador social refere-se à composição das famílias aqui abordadas, bem como os arranjos familiares que as caracterizam (estado civil).

A pesquisa revelou que $14,29 \%$ dos representantes vivem sozinhos na Casa, sendo este solteiro; salienta-se também que o mesmo percentual foi identificado na terceira opção elencada no questionário, a qual se refere à composição familiar por 5 pessoas cujo estado civil se apresenta como união estável; mas algo importante também a destacar é o fato de que 71,43\% das famílias são constituídas por mais de 6 pessoas, sendo $28,58 \%$ sob o estado civil de Casado, 14,29 \% Viúvo e 28,58\% por União Estável.

Desse modo é importante salientar que estas famílias formadas por mais de 6 pessoas são constituídas por pelo menos mais de um arranjo familiar. Ou seja, além de haver a presença das pessoas de referência da família (pai e mãe) e filhos, há ainda, os filhos dos filhos e marido/mulher destes filhos.

Essa realidade demonstra que dentro de um grupo familiar existem outras pequenas unidades familiares. Ocorre que a maioria destas famílias, se não

\footnotetext{
${ }^{9}$ A criação de indicadores sociais que pudessem mensurar as condições de vida da população se deu por volta da década de 1960 nos Estados Unidos, mas foi na década de 70 que houve maior difusão e implementação de tais estatísticas em todos os países, as quais não pretendem verificar somente o crescimento econômico do país através do Produto Interno Bruto - PIB, mas verificar o seu desenvolvimento social. No Brasil a implementação de tais indicadores se deu em 1973 através do Instituto Brasileiro de Geografia e Estatística - IBGE.
} 
todas, mesmo sendo constituídas por outras unidades continuam sob a responsabilidade do chefe maior, que conforme a pesquisa $42,86 \%$ destes chefes são mulheres e $57,14 \%$ são homens.

Outro indicador social se refere ao grau de instrução dos chefes das famílias indígenas residentes na Casa de Trânsito. Destes chefes 28,57 \% nunca frequentaram escola; 42,86 \% possuem o Ensino Fundamental Incompleto e 28,57 \% pessoas possuem o Ensino Médio Incompleto. Esses dados evidenciam que os chefes das sete famílias que residem permanentemente na Casa de Trânsito Indígena não concluíram seus estudos, conforme rege o ensino regular fundamental e médio. O principal motivo aferido se refere à falta de oportunidades de estudo em suas comunidades.

Para complementar a análise acerca da situação de escolarização dos chefes das famílias residentes na Casa de Trânsito, procurou-se verificar se este grupo se mantinha na escola ou se vindo para cidade buscou continuar ou dar início a sua escolarização. Em conversa com estes indígenas tomou-se conhecimento que aqueles que tiveram oportunidade de estudar, o fizeram em terras urbanas, inclusive através da Educação de Jovens e Adultos - EJA: “ $N a$ área o estudo no men tempo era sempre difícil, aí eu vim pra cidade estudar... mas aí né... eu acabei desistindo e depois que eu arrumei filho ficou mais difícil ainda, eu passei um tempo estudando na EJA, mas era muito longe e difícil e tinha os filhos, ai desisti" (MARIA, ENTREVISTA, 2011).

Conforme a fala desta chefa de família, que há dez anos reside na Casa de Trânsito, na área indígena certamente por volta de vinte anos atrás, existiam poucas escolas e possivelmente mínimas oportunidades de estudo. Assim, vindo para cidade buscam como opção a escolarização por meio de um sistema de aceleração das séries através de disciplinas modulares. Ocorre que nem sempre estes costumam terminar estes estudos, ainda que de forma acelerada. 
Outra situação encontrada, frente à falta de escolarização oficialmente reconhecida, é a perda de oportunidades de empregos:

\begin{abstract}
Comprovadamente, maiores níveis de escolaridade garantem melhores oportunidades de inserção qualificada no mercado de trabalho. Portanto, é importante verificar se as pessoas economicamente ativas têm uma escolaridade de pelo menos 11 anos de estudo completos, equivalente ao ensino médio, nível que atualmente é exigido para praticamente todos os postos de trabalho no mercado formal (IBGE, 2010, p. 49).
\end{abstract}

Nesse sentido, acredita-se que os indígenas chefes das famílias residentes na Casa, certamente, encontram maiores dificuldades para conseguir emprego do que aqueles que possuem o Ensino Médio ou nível superior completo. Para verificar tal assertiva apresentamos os indicadores sociais referentes à situação de trabalho e renda.

Das famílias entrevistadas $71,43 \%$ atualmente são autônomas, sendo que destas 42,86\% tem como renda familiar menos de um salário mínimo e 28,58\% até um salário mínimo; pudemos verificar que 28,57\% são aposentados, porém destes 14,28\% tem como renda um salário mínimo; $14,28 \%$ têm como renda dois salários mínimos ou mais.

Conforme os dados apresentados, evidenciamos que estas famílias têm como fonte de renda o emprego informal. A principal atividade laboral desenvolvida pelos indígenas residentes na Casa de Trânsito é o artesanato, sendo este o instrumento da geração de renda para os indígenas da Casa. Estas famílias trabalham com o artesanato, mas não recebem incentivo, principalmente material para uma maior produção.

A pesquisa também revelou que outra fonte de renda das famílias cuja situação de trabalho foi identificada como autônoma diz respeito aos programas 
de transferência de renda ou benefício social. Das famílias residentes na Casa de Trânsito 20\% recebe Benefício Social e 80\% estão inscritas em programas de Transferência de Renda, nesse caso o Programa Bolsa Família. As famílias residentes na Casa de Trânsito sobrevivem em grande parte do dinheiro do Programa Bolsa Família, uma vez que nem sempre a comercialização do artesanato consegue cobrir todas as despesas financeiras das mesmas.

O acesso aos serviços de saúde, levando em consideração a cobertura dos serviços segundo a óptica dos indígenas, foi outro indicador social utilizado por esta pesquisa. A pesquisa revelou que $28 \%$ das famílias quando acometidas por enfermidades recorrem aos centros de saúde existentes no município de Parintins; 29\% recorrem à equipe da CASAI/SESAI e 43\% utilizam os hospitais.

Com base nos dados apresentados, evidenciamos que os índios saterémawé urbanos costumam se utilizar mais dos serviços de saúde oferecidos pelo SUS do que pelo órgão indigenista, no caso a Secretaria Especial de Saúde Indígena - SESAI. Este fato se dá por dois motivos, a saber:

A SESAI não é responsável pelo atendimento dos indígenas que residem em área urbana, apresentando assim, resistência quando os indígenas urbanos buscam por seus serviços; outro motivo se refere ao fato de que os indígenas costumam buscar atendimento médico somente quando estão acometidos por enfermidade, por isso, geralmente buscam a emergência dos hospitais existentes no município. Conforme nos revelou uma de nossas informantes: "Nossas crianças de vez em quando ficam doentes, mais é de gripe. Ai a gente leva no posto que tem aqui perto, quando a agente de saúde marca a consulta para nós ou nós corremos na CASAI. Mas, tem vez que nós levamos na emergência mesmo, porque lá tem médico e atende rápido a gente". (MARIA, ENTREVISTA, 2011).

A fala desta indígena demonstra que a busca por serviços de saúde nos hospitais é uma prática comum entre os índios da Casa, uma vez que no setor de emergência dos hospitais os médicos estão de plantão, sem necessitar marcar 
previamente uma consulta. Contudo, verificamos que este serviço, assim como os demais são vistos com certa insatisfação pelos moradores da Casa, quando questionamos a respeito de como estes consideram o acesso à saúde no município.

De acordo com o senhor José: "A saúde é complicada aqui na cidade. Nós costumamos enfrentar dificuldades quando vamos na $C A S A I$ ou no hospital, porque demora muito o atendimento. É isso, no hospital demora muito para o médico atender o índio e na CAS AI não é toda hora que a gente pode contar" (ENTREVISTA, 2011).

A fala deste indígena demonstra que ao se buscar os serviços de saúde encontram dificuldades que comprometem a saúde destes, uma vez que os atendimentos são demorados e por vezes negados pela CASAI/SESAI.

Por último, apresentam-se como indicador social as condições de moradia na Casa. Assim, buscamos avaliar estas condições a partir do modo de viver indígena. Por isso, questionou-se aos indígenas, a sua visão a respeito das condições de moradia da referida Casa. Assim, evidenciamos que 14\% das famílias consideram as condições de moradia da Casa de Trânsito Indígena Ótima; 28\% consideram Boa; 29\% consideram Regular; o mesmo percentual foi verificado para a opção Precária.

Frente à exposição destes dados, verificamos que os indígenas, em sua maioria, não estão satisfeitos com as condições de moradia da Casa, principalmente no que se refere ao aspecto estrutural. A estrutura física da Casa é a principal reclamação dos indígenas, tanto que já foi alvo de denúncia nos meios de comunicação local e inclusive nacional. Fato que foi observado em uma de nossas visitas a Casa.

No entanto, acredita-se que a situação de maior vulnerabilidade dos moradores da Casa de Trânsito se dê com relação à segurança da posse/permanência no espaço, pois este foi cedido para os indígenas em ordem de comandato pela Diocese Católica de Parintins. De acordo com a indígena Joana: 
"De vez em quando ocorrem alguns conflitos aqui. Uma pessoa que mora aqui fez algumas denúncias na rádio e para a igreja e o bispo já falou que nós vamos ter que sair daqui”" (ENTREVISTA, 2011). Sendo assim, percebe-se que os indígenas não tem nenhuma segurança com relação a sua permanência nesse lugar.

Diante dos indicadores elencados acima verificou-se que as famílias residentes na Casa de Trânsito Indígena enfrentam dificuldades financeiras e de acesso aos serviços de saúde e de educação. Verificamos também que na cidade estas pessoas não têm perspectivas de emprego formal e se apoiam na renda oriunda de Programas de Transferência de Renda do governo federal, assim também como do artesanato por estes produzidos. Contudo, embora tenham o artesanato como um instrumento de resistência e afirmação étnica, não possuem incentivos materiais, financeiros, enfim, que pudessem alavancar sua produção.

Quando indagadas a respeito da vontade de voltar para a sua comunidade de origem, com exceção de uma família, todas manifestaram este desejo, porém a razão para que estas famílias não voltem para sua comunidade é a busca por melhores condições de acesso aos serviços de saúde e de educação, fato que se revela como uma contradição conforme os dados apresentados na pesquisa. Contudo, viver na cidade se tornou uma condição que estes não apontam previsão de volta para a comunidade, embora o retorno para as comunidades de origem se constitua como um ideal de vida.

\section{Considerações Finais}

Os povos indígenas são possuidores de uma cultura que respeita o próximo, a natureza e a si mesmo. Seu ethos é guiado por um espírito de reciprocidade coletiva que determina as suas relações sociais. Assim, passando a ter contato com a sociedade envolvente, estes, em um primeiro momento, estranham-na, mas a absorvem na tentativa de conseguir sobreviver na selva cercada por prédios. 
Quando da elaboração deste trabalho nos defrontamos com uma realidade torpe enfrentada pelos índios sateré-mawé urbanos residentes em Parintins, a qual reflete a forma histórica como os indígenas são vistos e tratados na sociedade ocidental.

Evidenciamos que o fenômeno da migração é frequente entre os saterémawé e que inclusive é um processo cultural que ocorre desde suas origens étnicas. Mas, além desse fator cultural outros tem se apresentado como determinantes da migração cada vez mais frequente dos sateré-mawé para a Casa de Trânsito Indígena de Parintins. Entre estes está a busca pelos serviços de saúde, a qual se dá em razão da ausência nas comunidades de suporte médico e material para aqueles que possuem doenças que necessitam de atenção médica contínua e permanente. Nesse processo está também a busca por educação, neste caso a formação escolar dos filhos, uma vez que na maioria das comunidades o ensino vai até as séries iniciais do Ensino Fundamental.

Frente a essa busca os indígenas tem se deslocado para Parintins, porém verificamos que há uma contradição entre o vir para a cidade buscar melhores condições de acesso à educação e saúde, e o estar na cidade vivenciando péssimas condições de atendimento, principalmente no que se refere aos serviços de saúde.

Além disso, evidenciamos que as famílias residentes na Casa de Trânsito Indígena de Parintins vivenciam situação de pobreza, haja vista que seis destas sete famílias sobrevivem com até um salário mínimo com mais de seis pessoas entre crianças, adolescentes, jovens, adultos e idosos. $\mathrm{Na}$ cidade, estas pessoas não têm perspectivas de emprego, e a renda é oriunda, em sua maioria, dos programas de transferência de renda do Governo Federal e da comercialização do artesanato produzido por estes.

O artesanato, neste caso, foi considerado como algo positivo, pois além de ser uma geração de renda para os índios sateré-mawé é também instrumento de afirmação da identidade étnica desse coletivo. No entanto, verificamos que 
não há incentivos financeiros para os indígenas moradores na Casa possam alavancar suas vendas, embora exista um lugar reservado para a comercialização de seus produtos.

Como reflexão final implica chamarmos à atenção para a importância do fomento de políticas públicas voltadas para esta camada da população brasileira que se junta aos grupos considerados vulneráveis. Os sateré-mawé urbanos enfrentam em seu cotidiano as mais complexas refrações da questão social e não bastasse isso, são relegados a uma condição de tutelados.

\section{Referências}

ALVAREZ, Gabriel O. Satereria: Tradição e Política Sateré-Mawé. Manaus: Editora Valer/CAPES/PRODOC, 2009.

BERNAL, Roberto Jaramillo. Índios Urbanos: processo de reconformação das identidades étnicas indigenas em Manaus. Tradução de Evelyne Marie Therese Mainbourg. Manaus: Editora da Faculdade Federal do Amazonas/Faculdade Salesiana Dom Bosco, 2009.

BRASIL. Lei $\mathrm{n}^{\circ} 6.001$ de 19 de dezembro de 1973. Dispõe sobre o Estatuto do Índio. Publicado no Diário Oficial de 21 de dezembro de 1973.

IBGE - Instituto Brasileiro de Geografia e Estatística. Sintese de Indicadores Sociais: uma análise das condições de vida da população brasileira 2010. IBGE: Rio de Janeiro, 2010.

LORENZ, Sônia da Silva. Sateré Mawé: os filhos do guaraná. São Paulo: Centro de Trabalho Indigenista. 1992.

PEREIRA, Nunes. Os Índios Maués. 2. ed. rev. Manaus: Editora Valer e do Governo do Estado do Amazonas, 2003.

RAMOS, Alcida Rita. Sociedades Indígenas. 5. ed. São Paulo: Ática, 2001.

TEIXEIRA, P. (Org.) Sateré-Mawé: retrato de um povo indigena. Manaus: UNICEF/FNUAP, 2005.

TEIXEIRA, P; SENA, R. R. As migrações entre os Sateré-Mawé, povo indígena da Amazônia Brasileira. In: ENCONTRO NACIONAL DE ESTUDOS POPULACIONAIS, 16, 2008, Caxambu, Anais. Campinas: ABEP, 2008. 